\title{
Study on Logistics Supply Chain of Agricultural Products from Perspective of Risk Management and Control
}

\author{
Junde Han \\ Tianjin Agricultural University, Tianjin, 300384, China
}

Keywords: Risk management and control, Agricultural products, Logistics supply chain

\begin{abstract}
With the constant progress and expansion of agricultural products, the trade volume of agricultural products has increased gradually and market demand has been expanded. However, the fast and safe circulation of agricultural products is hindered seriously by the concept of attaching importance to production while neglecting circulation. This paper starts from the current status and features of logistics supply chain of agricultural products, analyzes risk factors influencing logistics supply chain of agricultural products, puts forward reasonable countermeasures and guarantees that they can improve the growth rate of agricultural products and promote agricultural development.
\end{abstract}

\section{Introduction}

Risks refer to uncertain losses. The consequence and probability of uncertain risks are determined according to the actual degree of risks. In terms of supply chain risk, corresponding risks cannot be predicted during product manufacturing of enterprises due to various factors, thus causing problems between expected earning and actual earning and greatly influencing enterprise benefits. Due to the constant increase of supply chain scale, enterprises need more talents and a complicated supply chain structure occurs. Therefore, the degree of supply chain risk increases. The entry of China into WTO has greatly changed market environment. The constant improvement of economic system, science and technology and economic globalization produces great influence on the development of supply chain of agricultural products.

\section{Development status and features of logistics supply chain of agricultural products}

Agricultural products depend too much on natural conditions, natural force and individual life of crops and have obvious dispersiveness, seasonality and regionality in the production process. Meanwhile, agricultural products are vivid. People cannot be separated from fresh agricultural products in their daily life with small flexible consumption. Consumption dispersiveness and universality exist. As agricultural products have certain characteristics, logistics supply chain of agricultural products has the following features compared to industrial logistics supply chain: first, great market uncertainty; second, unbalanced market power; third, high asset specificity of supply chain of agricultural products; forth, higher requirements for logistics of agricultural products. In the current stage, the main core constituting the supply chain of agricultural products is wholesale market. It includes wholesale market, peasant households, consumers, supermarkets, trading market of agricultural products and production and processing enterprises. The basic process is shown as below:

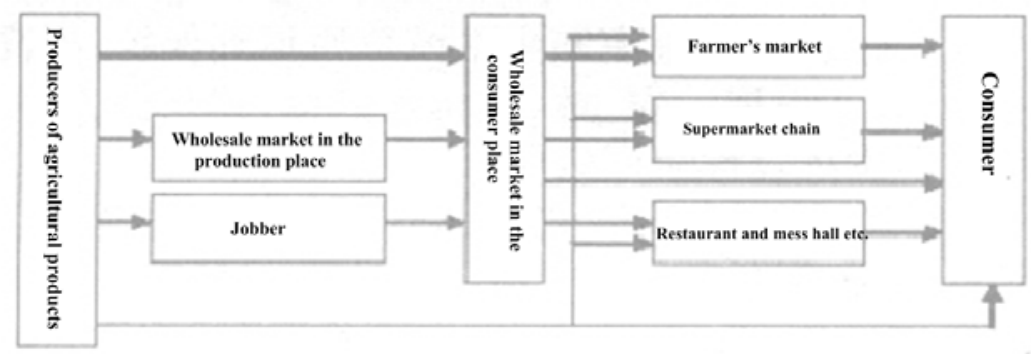

Fig.1 Circulation chart 
Producers, farm market, wholesalers of transportation and sale, sales market, retailers and consumers are included in the logistics pattern of agricultural products based on the circulation above. Several issues about agricultural product circulation can be analyzed: first, wholesale market with incomplete development; second, relevant issues of logistics cost and safety of agricultural products; third, unordered logistics of agricultural products; forth, dislocation between production and need in the logistics supply chain of agricultural products; fifth, the main retail method is farmer's market, but the safety of agricultural products cannot be guaranteed; sixth, information lacking smoothness between nodes of supply chain; seventh, problems of logistics technology ${ }^{[1]}$.

\section{Risk factors influencing supply chain of agricultural products}

\section{Supply risk}

Supply risk refers to the failure to operate downstream enterprises normally due to the uncertainty of supply source, which influences the overall supply chain of agricultural products. Due to strong seasonality and dispersiveness of agricultural products in the production process, the market cannot be fully monopolized and operators cannot guarantee the quantity and quality of products completely, thus causing risks of supply chain. When analyzing supply risk, it is necessary to use the quality and quantity of agricultural products as basic indicators.

\section{Demand risk}

The main guidance is market demand in the operational process of supply chain of agricultural products. The transportation, production, sales and supply of supply chain of agricultural products are established under the premise of accurate prediction, which intensify market competition constantly, increase uncertain consumer and market preference greatly, improve prediction difficulty and increase operational risks of agricultural products. Therefore, consumer preference and market uncertainty are used as basic indicators of demand risk.

\section{Cooperation risk}

Compared to other risks, cooperation risk has invisible influence on supply chain of agricultural products, which cannot be quantified. Principal-agent phenomenon occurring in the supply chain of agricultural products with cooperative relationship is mainly adverse selection and moral risk problem. In addition, due to different management system, decision and culture of enterprises in the supply chain, more uncertain factors occur in the process of cooperation, thus incurring cooperation risk. Main indicators of cooperation risk include price risk, coordination mechanism, cultural difference, benefit distribution and moral hazard.

\section{Information risk}

Most enterprises providing nodes for agricultural products belong to basic industry. The reduction of use of modern information technology causes the failure to guarantee the ability of delivering supply chain information of agricultural products smoothly. The constant increase of supply chain size and the complicated structure will increase the probability of information error to a certain extent and cause information delay or distortion. In addition, members of supply chain are regarded as basic independent subjects for operation. It is unrealistic to allow enterprises to share private information completely, which will cause information risk. Therefore, information sharing, information authenticity and information transfer speed are important indicators of information risk.

\section{Environmental risk}

Due to uncertain external factors, supply chain of agricultural products will bring certain risks to the whole. External factors mainly include natural environment, politics and economy etc. Therefore, main indicators of environmental factor are political influence, economic crisis and natural disaster which form corresponding environmental risks. 


\section{Logistics risk}

Agricultural products are easy to decay. Relevant services of logistics supply chain of agricultural products with higher requirements are required. To increase the operation efficiency of agricultural products effectively, a high-efficient logistics system should be possessed. At this time, enterprises in the supply chain should take the countermeasure of joint solution reasonably. However, it is very difficult to achieve in practical operation. Enterprises in the supply chain will have cohesion error, delivery delay and loss of agricultural products. Main indicators of logistics risk include product loss and delivery delay ${ }^{[2]}$.

\section{Evaluation of risks of agricultural product supply chain}

\section{Evaluation with exponential method}

In quantified evaluation of risks of agricultural product supply chain, it is required to estimate serious consequences of influencing factors of supply chain risks according to corresponding indicators, evaluate the possibility grade of risk occurrence according to relevant indicators and standards, make a combination with the table below and analyze the possibility and severity comprehensively so as to obtain potential risk index.

Table 1

Risk Index Evaluation Matrix

\begin{tabular}{|c|c|c|c|c|c|}
\hline \multirow{2}{*}{\multicolumn{2}{|c|}{ Risk index }} & \multicolumn{4}{|c|}{ Severity grade } \\
\hline & & \multirow{2}{*}{$\begin{array}{l}\text { Disastrous } \\
2\end{array}$} & \multirow{2}{*}{$\begin{array}{l}\text { Serious } \\
5\end{array}$} & \multirow{2}{*}{\begin{tabular}{|l} 
Moderate \\
9
\end{tabular}} & \multirow{2}{*}{\begin{tabular}{|l|} 
Mild \\
13
\end{tabular}} \\
\hline 0 & Likely & & & & \\
\hline 恶. & Possible & 4 & 6 & 11 & 18 \\
\hline : & Unlikely & 8 & 10 & 14 & 19 \\
\hline 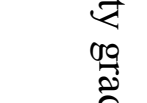 & $\begin{array}{l}\text { Very small } \\
\text { possibility }\end{array}$ & 12 & 15 & 17 & 20 \\
\hline$\frac{2}{8}$ & Frequent & 1 & 3 & 7 & 13 \\
\hline
\end{tabular}

According to the table above, there can be three categories of potential risk index: first, problems with a great danger (risk index $\leq 5$ ), which should be prevented with all efforts so as to minimize danger level; second, problems with moderate danger $(12>$ risk index $>5)$, which should be prevented with countermeasures; third, problems with low risk (risk index $\geq 12$ ), which can be prevented with simple measures.

\section{Reliability evaluation matrix}

The method of analyzing risks of agricultural product supply chain with reliability evaluation matrix can be divided into four steps: first, select evaluation factors reasonably and establish evaluation factor set; second, grade rationally according to actual evaluation specification and establish evaluation standard on this basis; third, evaluate risk factors of supply chain of agricultural products independently and obtain the corresponding weight matrix and evaluation matrix; forth, use mathematical phrases to calculate the actual result of risk evaluation factors rationally and define the reliability in supply chain of agricultural products.

$$
\mathrm{R}_{\mathrm{i}}=\sum_{\mathrm{j}=1}^{\mathrm{m}} \mathrm{p}_{\mathrm{j}} \mathrm{a}_{\mathrm{ij}}, \mathrm{i}=1,2, \cdots, \mathrm{n} ; \mathrm{j}=1,2, \cdots, \mathrm{m}
$$

Where $\mathrm{a}_{\mathrm{ij}}$ refers to the assessed value of risk factor $\mathrm{j}$ in supply chain $\mathrm{i}$ of agricultural products; $\mathrm{R}_{\mathrm{i}}$ refers to the weight of risk factor. $P s=R_{1}, R_{2}, \ldots . R m$ refers to the reliability of the overall supply chain of agricultural products. Ps refers to reliability. 


\section{Preventive measures for management of risks in supply chain of agricultural products}

This paper analyzes actual risks of supply chain of agricultural products and puts forward the following measures for preventing and managing risks in the supply chain of agricultural products rationally according to the development status and features of supply chain of agricultural products.

\section{Establish food refrigeration, circulation and fresh keeping supply chain so as to reduce supply chain risks}

To reduce losses incurred by supply chain risks of agricultural products caused by technical level reasonably, we can determine the basic logistics form of agricultural products to a certain extent, i.e. natural logistics or normal-temperature logistics and establish food refrigeration, circulation and fresh keeping supply chain. First, use and study built-up refrigeratory and refrigerator van, the main core of which is actually modern cold-chain transportation system; second, use temperature control device reasonably in processing workshop so as to protect agricultural products from the influence of external environment during processing; third, manage and standardize refreshing time and shelf life effectively according to advanced information technology and implement "first-in first-out" rule for food; forth, achieve the purpose of integrating supply chain information with information technology rather than allow one enterprise to complete food refrigeration, circulation and fresh keeping supply chain. Relevant departments should play a role, e.g. give preferential policies and increase investment and construction speed ${ }^{[3]}$.

\section{Increase informatization management level of agricultural products and reduce information risk effectively}

Establishing a public platform of logistics information under the management mode of supply chain of agricultural products in organic combination with e-commerce is an important means for supply chain management that can improve the level of informatization of agricultural products effectively and rationally. Due to the constant development of science and technology, e-commerce has developed rapidly and e-commerce of agricultural products has gradually developed into an important way for analyzing the level of informatization of supply chain. In the current stage, the supply of agricultural products under e-commerce mode can be divided into virtual business alliance mode, network cooperation mode, network transaction mode and information mode. The establishment of information platform can greatly develop e-commerce to a certain extent, reduce transaction cost of supply chain, improve the quality and speed of information transmission and improve the situation of supply chain of agricultural products with low informatization level in the current stage. Therefore, it is necessary to use network information technology in the supply chain, increase the speed of integrating e-commerce and supply chain of agricultural products organically and establish a complete network management mechanism of supply chain of agricultural products.

\section{Improve the development of core enterprises in the supply chain of agricultural products and reduce risks effectively}

It can be found through a lot of practice that an enterprise of the initiator should exist and become the core of supply chain production place in the future when agricultural product supply chain is established. Good operation of supply chain and competitiveness are key to determining the possession of core coordinating capacity of an enterprise. The development of core enterprises can be analyzed in the following aspects: first, select suppliers rationally in strategic aspects, establish certain strategic relationship with vital partners and study backup suppliers appropriately; second, minimize the time to market with the method of access to customers and direct selling so as to obtain information and reduce risks; third, simplify supply chain as much as possible, i.e. reorganize the supply process of enterprises according to supply chain nodes of agricultural products, establish a trans-enterprise team with core boundary, constantly establish and improve daily strategic plan and production plan and guarantee the standardization of product components and parts; forth, establish certain benefit compensation system so as to make corresponding compensations for individual enterprises subject to profit loss as much as possible when meeting actual market objectives; fifth, 
optimize the management of supply chain mechanism of agricultural products constantly according to advanced information management method and modern communication technology so as to guarantee cooperative work of member enterprises of supply chain and achieve the effect of information sharing ${ }^{[4]}$.

\section{Improve and establish an organization of safety supply of agricultural products and reduce quality risks effectively}

Compared to developed countries, China has developed the supply chain of agricultural products late and certain safety system has not formed. Various aspects, especially consumers, start to pay attention to food safety issue of supply chain of agricultural products. How to guarantee and establish food safety organization effectively and achieve the purpose of reducing quality safety risks can be analyzed as below: first, improve the construction of agricultural product market mechanism and the safety of food available in the market; second, standardize management behaviors of core enterprises; third, strengthen education and publicity and fully recognize and guarantee food quality safety; forth, accelerate the study and application of food control information tracking mechanism; fifth, improve functions of relevant organizations and associations constantly and strengthen the consciousness and self-discipline awareness in food safety production process; sixth, guarantee consistent food supply construction system and food safety policies; seventh, establish a unified quality safety standard and logistics standard and strengthen the monitoring over agricultural products effectively ${ }^{[5]}$.

\section{Conclusion}

In short, this paper analyzes several risk factors influencing supply chain with reliability evaluation matrix and exponent method based on the development status and features of supply chain of agricultural products and puts forward risk management measures for logistics supply chain of agricultural products so as to promote the development and progress of agricultural product industry to a certain extent.

\section{Acknowledgments}

This paper is philosophy and social science fund of Tianjin; name: Study on Establishment of Standardization Operation System of Local Vegetable Logistics in Tianjin; No. TJYY13-026

\section{References}

[1] $\mathrm{Hu}$ Yifeng, Zhang Youhua, Li Shaowen et al. Study on Application of Internet of Things in Logistics of Agricultural Products. Collected Papers of Academic Annual Conference of Special Committee of Electrical Information and Automation of Chinese Society of Agricultural Engineering and Special Committee of Science and Education of Rural Electrification Branch of Chinese Society of Electrical Engineering in 2010. 2010:1-4.

[2] Zhao Zhitian, Yang Jianzheng. Theoretical Framework, Test and Development Strategies of Logistics of Agricultural Products in E-business Environment - Data from Lishui, Zhejiang. China Business and Market, 2014(6):108-113.

[3] Xu Jie, Liu Pengfei, Zhou Zheng et al. Establishment and Realization of Logistics Tracking Management System of Agricultural Products with Tropical Features Based on Supply Chain. Agricultural Science and Technology: English Edition, 2011,12(9):1308-1312.

[4] Wang Ning, Huang Liping. Study on Management Mode of Logistics Supply Chain of Agricultural Products Based on Information Network. Study of Agricultural Modernization, 2010,26(2):126-129,144. 
[5] Xu Jie, Liu Pengfei, Zhou Zheng et al. Establishment and Realization of Logistics Tracking Management System of Tropical Agricultural Products Based on Supply Chain. Anhui Agricultural Science, 2010,38(32):18479-18482. 